\title{
Diagnostic Procedures, Clinical Characteristics and Counseling in Cystic Fibrosis
}

\author{
Kris De Boeck \\ Department of Pediatrics, University of Leuven, Leuven, Belgium
}

\author{
Key Words \\ Cystic fibrosis - Sweat test - CFTR mutation - Nasal \\ potential difference measurement $\cdot$ Salt loss syndrome . \\ Pseudomonas aeruginosa $\cdot$ Pancreatic insufficiency · \\ Male infertility
}

\begin{abstract}
Most patients with the eventual diagnosis of cystic fibrosis (CF) present in the first months of life with classical symptoms such as meconium ileus, failure to thrive and recurrent or persistent cough. Disease manifestations are obvious, progressive and concern different organ systems. In these patients the standard diagnostic test is the sweat test. A sweat chloride concentration of $>60 \mathrm{mmol} / \mathrm{l}$ confirms the clinically suspected diagnosis. Since the discovery of the CFTR (CF transmembrane conductance regulator) gene, it has become obvious that the clinical spectrum is broad. Several categories of patients have been proven to carry two CFTR mutations: patients with classic CF; patients with milder symptoms and disease onset during adolescence or even adulthood; patients with a single clinical feature, e.g. recurrent pancreatitis, sclerosing cholangitis, 'idiopathic' bronchiectasis, and male infertility. The latter two categories are described as atypical or non-classic CF. It is very important that these patients know that they do not suffer from classic CF, but that they have a risk factor for developing a CF-like disease that warrants intermittent follow-up by physicians familiar with the very wide disease spectrum. In patients with
\end{abstract}

classic CF, chronic progressive bacterial sinopulmonary infection and inflammation with intermittent exacerbations are the most typical disease manifestations. Ninety percent of patients have pancreatic insufficiency. Postpubertal men are sterile. During their lifetime CF patients may develop disease manifestations and complications in the sinuses, lung, pancreas, liver, intestine, esophagus, bone, joints, etc. The complex mix of possible disease manifestations makes each patient unique. As they become older, the number of complications tends to increase and their physical condition tends to worsen. Many young adult CF patients have decreased exercise tolerance because of advanced lung disease; $20 \%$ have CF-related diabetes mellitus. Classic CF is a life-shortening disorder and, even with the most intense treatment and follow-up, the current median survival is around 34 years. This puts an enormous psychological stress on patients and families. Counseling to prevent disease recurrence in siblings and in the extended family is important and complex. Copyright $\odot 2006$ Nestec Ltd., Vevey/S. Karger AG, Basel

\section{Introduction}

Cystic fibrosis (CF) is the most common life-shortening hereditary disorder in Caucasians. The incidence in newborns varies considerably according to the ethnicity of the population studied. Since the discovery of the CFTR (CF transmembrane conductance regulator) gene,

\begin{tabular}{ll}
\hline KARGER & ( ) 2006 Nestec Ltd., Vevey/S. Karger AG, Basel \\
0517-8606/06/0643-0119\$23.50/0 \\
$\begin{array}{l}\text { Fax +41 61 306 12 34 } \\
\begin{array}{l}\text { E-Mail karger@karger.ch } \\
\text { www.karger.com }\end{array}\end{array}$ & $\begin{array}{l}\text { Accessible online at: } \\
\text { www.karger.com/ane }\end{array}$
\end{tabular}


it has become obvious that CF occurs in every population studied so far and that the incidence has rather been underestimated in non-Caucasians [1].

$\mathrm{CF}$ is an autosomal recessive hereditary disease caused by one mutation on each of the genes encoding the CFTR protein. CF is a multi-organ disease. Symptoms are the result of deficient chloride transport across the epithelia of exocrine glands because of the absence or dysfunction of the cAMP-activated CFTR chloride channel [2].

The vast majority of patients present disease manifestations at birth or during the early months of life. They do not pose a diagnostic challenge provided the diagnosis is considered and a sweat test performed in an experienced laboratory. Some patients have much milder disease types and pose a major diagnostic challenge. They may have variable symptoms. In these patients, the sweat test result will often be inconclusive. Additional diagnostic tests help to come to a conclusion, i.e. a search for two disease-causing CFTR mutations or physiological evidence of CFTR protein dysfunction [3].

\section{Symptoms Leading to the Diagnosis of CF}

Since CF is the most common serious hereditary disease in Caucasians, it should be considered often in the differential diagnosis of infants with recurrent or persistent symptoms of different types. Many symptoms can indeed be the first manifestation of CF.

After birth, vomiting and not passing stools occurs in $10-15 \%$ of CF infants [4]. Meconium ileus is so specific to $\mathrm{CF}$ that the diagnosis is hardly ever missed. A less known neonatal manifestation is prolonged cholestatic jaundice [5]. The most common presentation is failure to thrive because of exocrine pancreatic insufficiency often in combination with chronic cough [6]. On the other hand, normal digestion may be preserved during months to years [7].

Recurrent or persistent cough and recurrent or chronic chest infections can start during infancy and childhood. The onset of chronic cough is often triggered by a viral infection such as respiratory syncytial virus [8].

Salt loss syndromes are mainly seen in warm climates. Heat stroke with dehydration and electrolyte imbalance due to excessive salt loss may lead to the diagnosis [9]. But also in temperate climates infants can present with apathy, poor intake, vomiting, poor weight gain and Bartter-like polyuria due to hypochloremic alkalosis and hypokalemia secondary to insufficient salt intake [9].
When the diagnosis is missed in early childhood, disease complications may occur and eventually lead to the diagnosis: clubbing, bronchiectasis, chronic sinusitis, nasal polyps, liver cirrhosis, hematemesis, hemoptysis, etc. But the list of manifestations leading to the diagnosis of $\mathrm{CF}$ is long (table 1). An unresolved pregnancy wish in a couple leading to detection of azoospermia in the male partner due to bilateral absence of the vas deferens is the classic example of an atypical CF phenotype [10; Cutting, p. 113].

Every physician will readily put forward the diagnosis $\mathrm{CF}$ when asked for the cause of failure to thrive plus recurrent chest infections in an infant. Still the diagnosis is regularly missed or delayed even in patients with classic symptoms. The reasons for this may be manifold. The parents will phrase the chief complaint differently. They will not state: 'My child eats a lot, has fatty stools and does not gain weight'. But they may say: 'My child is fretful, difficult to soothe'. The parents may consult different physicians rather than return to the same physician with an unresolved problem. One symptom secondary to malabsorption may be pursued rather than the whole picture interpreted: edema and anemia with referral to a child nephrologist; hyperinflation, increased liver span and difficulty feeding with referral to the pediatric cardiologist; hematomas with referral to the child oncologist; perianal and perioral rash with referral to the dermatologist, and anemia and hemolysis with referral to the pediatric hematologist. All these situations have been reported [11]. In addition, children are often not acutely ill. The cough associated with chronic airway infection is initially not that pronounced but rather very persistent. Slowly and progressively respiratory distress increases. Many children present to the general practitioner with recurrent chest infections. He may dismiss the diagnosis CF because the child looks too healthy or does not have failure to thrive. The index of suspicion should be high in children with a chronic complaint. And certainly all children who can produce sputa, who have recurrent chest infiltrates, in whom cough only improves temporarily with antibiotic treatment, who are not without coughing during the summer, in whom asthma treatment is unsuccessful or who have clubbing should be investigated by the sweat test.

An early diagnosis is very important to delay disease progression. Therefore neonatal screening is advisable in countries that can afford the cost and/or especially in regions with a high mean age at diagnosis [12]. Neonatal screening is, however, not without problems since heterozygotes and children with dubious diagnoses will also be detected [13]. 
Table 1. Clinical manifestations suggestive of CF

\begin{tabular}{ll}
\hline Highly suggestive & Suggestive but less specific \\
\hline Gastrointestinal manifestations & \\
Meconium ileus & Failure to thrive \\
Exocrine pancreatic insufficiency in children & Hypoproteinemia \\
& Deficiency of lipsoluble vitamins \\
& Distal intestinal obstruction syndrome \\
& Rectal prolapse \\
& Biliary cirrhosis \\
& Portal hypertension \\
& Cholelithiasis in children without hemolytic disorder \\
& Primary sclerosing cholangitis \\
& Exocrine pancreatic insufficiency in adults \\
& Recurrent pancreatitis \\
\hline
\end{tabular}

Sinopulmonary manifestations

Persistent respiratory infection with mucoid Pseudomonas aeruginosa

Bronchiectasis in both upper lobes

Persistent respiratory infection with

Burkholderia cepacia

Nasal polyps in children
Persistent or recurrent respiratory infections with Staphylococcus aureus, P. aeruginosa, Achromobacter xylosoxidans or Haemophilus influenzae

Radiological evidence of bronchiectasis, atelectasis, hyperinflation or persistent infiltrates on chest X-ray Hemoptysis associated with diffuse pulmonary disease other than tuberculosis or vasculitis

Chronic and/or productive cough

Allergic bronchopulmonary aspergillosis

Nasal polyps in adults

Radiological evidence of chronic pansinusitis

Other

Hypochloremic alkalosis in the absence of vomiting

Congenital bilateral absence of the vas deferens
Digital clubbing

Osteopenia/osteoporosis below 40 years of age

Atypical diabetes

From De Boeck et al. [55] with permission from the BMJ Publishing Group.

\section{Diagnostic Tests Specific for CF}

Diagnostic confirmation of CF can be made by a sweat test, by DNA analysis of CFTR mutations or by CFTR bioassays. In settings where it is available, the reliable Gibson and Cooke [14] sweat test is the most appropriate initial diagnostic test because of its high yield: $98 \%$ of American CF patients have a positive sweat test [15]. The aim of a 'first-line' CFTR DNA test is to screen for the CF-causing CFTR mutations that are most prevalent in the population from which the patient originates, i.e.
CFTR mutations with a frequency of $>0.5 \%$. In most populations this will lead to detection of two mutations in $80-95 \%$ of patients [1]. In patients with atypical disease manifestations, the sweat test is often equivocal. Additional diagnostic tests will be necessary to substantiate the diagnosis: CFTR mutation analysis and, at times, CFTR bioassays.

\section{Sweat Test}

An accurately performed sweat test has a high diagnostic yield. However, this 'simple' test requires great ex- 
pertise and meticulous attention to detail. In many laboratories an insufficient number of tests are performed by too many different laboratory technicians so that errors are likely [16]. The quantitative pilocarpine iontophoresis sweat test developed by Gibson and Cooke [14] in 1959 remains the test of choice. After pilocarpine stimulation, sweat should be collected over $30 \mathrm{~min}$ onto pre-weighed gauze or filter paper low in sodium chloride $[3,14,17,18]$. A minimum sweat rate of $1 \mathrm{~g} / \mathrm{m}^{2}$ body surface area $/ \mathrm{min}$ is required; thus a sweat 'weight' of $50-100 \mathrm{mg}$ is adequate.

A sweat chloride concentration of $>60 \mathrm{mmol} / \mathrm{l}$ confirms the diagnosis of CF in patients with suggestive clinical symptoms. The cutoff value of $60 \mathrm{mmol} / \mathrm{l}$ discriminates reliably between normals and patients with CF [19]. A chloride value of $>60 \mathrm{mmol} / \mathrm{l}$ is nearly always associated with CF. There are few exceptions: values of $>60 \mathrm{mmol} / \mathrm{l}$ have been reported in a number of unusual skin disorders and rare endocrine or metabolic conditions that can be readily distinguished from CF. Even then, these mainly concern case reports. Normal sweat contains $<60 \mathrm{mmol} / \mathrm{l}$ chloride and sodium, usually even $<30 \mathrm{mmol} / \mathrm{l}$ [20]. The sweat test can be carried out from the $3 \mathrm{rd}$ week of life on, provided the infant weighs more than $3 \mathrm{~kg}$, is normally hydrated and without significant illness. For additional details about the sweat test we refer to consensus reports $[3,17,21]$.

A proportion of subjects carrying two mutations, one on each CFTR gene, have a sweat chloride concentration of $<60 \mathrm{mmol} / \mathrm{l}[22,23]$. There is not really an absolute lower cutoff value for the sweat chloride concentration that can exclude atypical CF cases [22], but most authors explore patients with chloride concentrations between 40 and $60 \mathrm{mmol} / \mathrm{l}$. One study focused on patients with chloride concentrations between 30 and $60 \mathrm{mmol} / \mathrm{l}$ [20] representing about $4 \%$ of symptomatic persons who underwent a sweat test. $23 \%$ of these patients were subsequently found to carry two CFTR mutations [20].

\section{Identifying CFTR Gene Mutations}

The CFTR gene, located on the long arm of chromosome 7, encodes the CFTR protein. This transmembrane protein acts as a cAMP-mediated chloride channel with many functions, an important one being the regulation of ion and water balance across epithelia [2; Donaldson and Boucher, pp. 103-109].

More than 1,500 CFTR mutations have been identified [24]. More than 1,000 mutations are reported in patients with CF symptoms. The remainder are involved in the milder CFTR-related diseases or do not cause disease at all [24]. For several mutations, i.e. most class I mutations (nonsense mutations, splice-site mutations, out-frame deletions/insertions), the CF-causing nature is obvious. For the remaining mutations, only functional studies unequivocally determine if they are CF-causing mutations. So far this has only been done for the most common CFTR mutations. A rare missense mutation found after complete screening of the CFTR gene can be either a polymorphism or a $\mathrm{CF}$-causing mutation [Cutting, p. 113].

$\mathrm{CF}$ is an autosomal recessive disease which means that a CF patient has a disease-causing mutation in both CFTR genes. A CF patient can be homozygous when carrying an identical CFTR mutation on both CFTR alleles, or compound heterozygous when carrying two different CFTR mutations.

The frequency of CFTR mutations differs between populations [1]. F508del is by far the most common mutation and is found on $70 \%$ or more of the CF chromosomes in northern European populations. Much lower frequencies for F508del are observed in southern European populations. Examples of other mutations that occur in most populations, with a frequency of around 12\% include: G542X, G551D, R553X, W1282X and N1303K. Finally, for a given population, ethnic-specific mutations that reach frequencies from $1 \%$ to even as high as $7 \%$ exist [25]. In most populations, these common mutations cover $80-95 \%$ of all mutant CFTR genes.

Commercial assays are available that screen for a panel of about 30 mutations with a prevalence above $0.5 \%$, the majority of which are associated with classic CF [26]. A mutation detection rate of $90 \%$ in a specific population signifies that a mutation will be identified on both CFTR genes in $81 \%$ of the typical CF patients; a mutation will be found on only 1 CFTR gene in $18 \%$, and no mutation will be found on either CFTR gene in $1 \%$.

In the case of a borderline sweat test in a patient with symptoms compatible with atypical CF, extensive mutation screening of both CFTR genes may be required to support this diagnosis. Only sequencing will approach $100 \%$ sensitivity. Even if a mutation is found, its involvement in disease may not be clear: for many CFTR mutations the functional consequences are unknown; they may be polymorphisms [24].

\section{CFTR Bioassays: Transepithelial Nasal Potential Difference}

$\mathrm{CF}$ is a disease caused by an absence or dysfunction of the apical CFTR protein responsible for CAMP-induced chloride secretion. In addition there is a compensatory 
Fig. 1. Nasal potential difference (PD) measurement in a healthy person (a) and a person with typical CF (b). In a healthy person the basal PD is negative ( -20 to $30 \mathrm{mV}$ ), rises moderately after application of amiloride and decreases obviously after application of a low chloride solution and isoproterenol. In a patient with typical CF, the baseline PD is more negative and the rise after application of amiloride is greater. There is no change in PD after application of a low chloride solution and isoproterenol. From De Boeck et al. [55] with permission from BMJ Publishing Group.
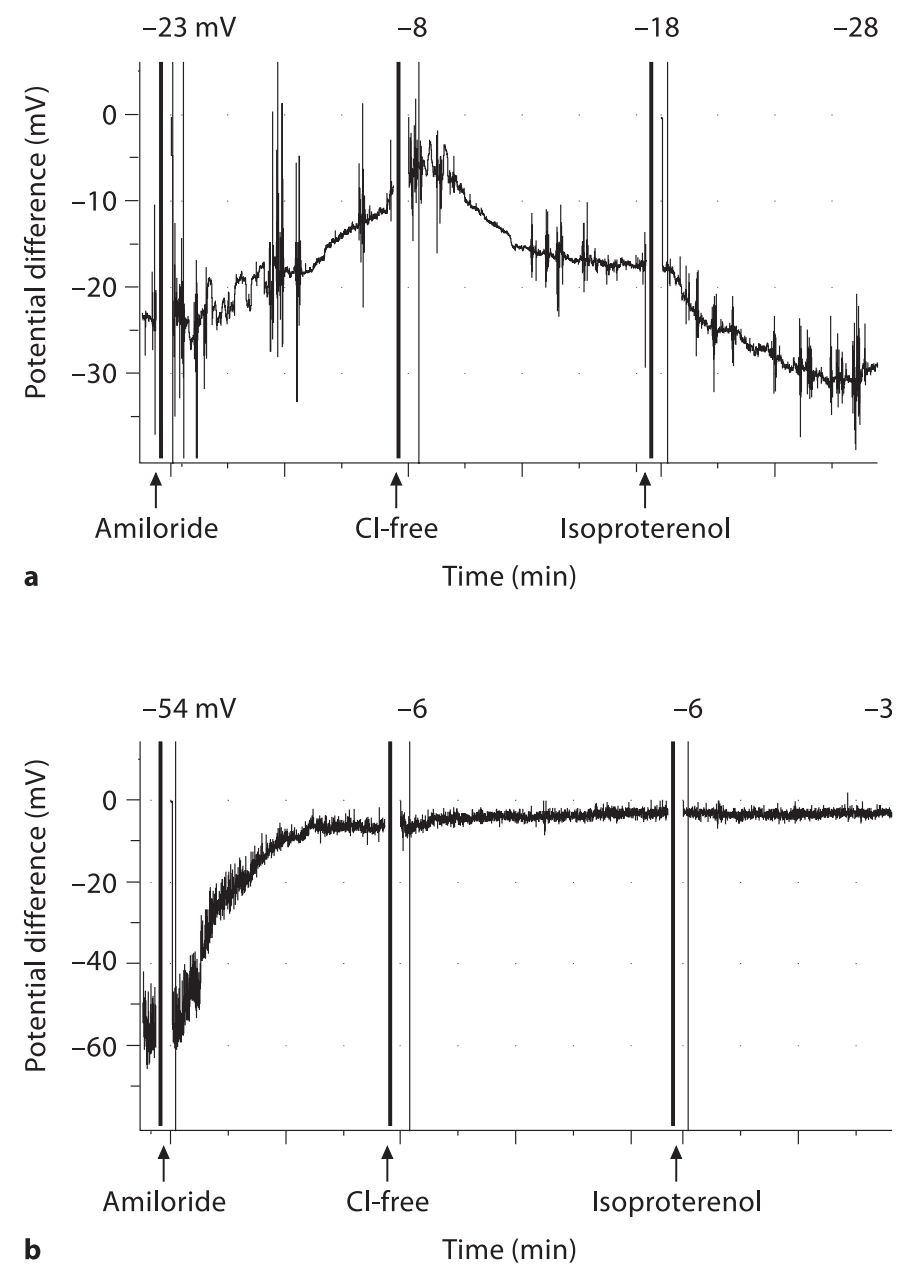

b excessive sodium influx into epithelial cells $[2,27]$. CFTR bioassays measure the epithelial ion fluxes or their resulting voltage potential at the mucosal surface [28]. These assays thus provide a direct view of the physiology at the cellular and the ion channel level and have been developed to help resolve diagnostic dilemmas in atypical patients by ruling in or out a CFTR-related dysfunction. The tests can be done on respiratory or intestinal epithelium; they are complex and require special equipment and expertise. The use of nasal potential difference (PD) as a diagnostic test for CF was already accepted in the diagnostic consensus of Rosenstein and Cutting [29] in 1998. The PD is measured between the nasal mucosa and the skin of the forearm. Practical details of this test have been published $[28,30]$. The basal PD gives an indication of sodium transport via the amiloride-sensitive epithelial sodium channel. Then the effect of blocking the epithelial sodium channel by amiloride superfusion is evaluated. Lastly a large chloride chemical gradient is generated across the apical membrane to measure epithelial chloride permeability.

The test has been introduced in clinical practice in many large CF centers that have compiled their own reference values. With skilled operators and careful attention to technical details, the nasal PD measurement can be standardized [31].

The nasal PD of a patient with classic CF is easily distinguishable from that of a healthy control person (fig. 1). 
Table 2. Factors known to influence disease progression

Fixed factors
Genotype
Sex
Pancreatic status
Polymorphisms and disease-modifier genes, e.g. TGF- $\beta$,
$\quad$ mannose-binding lectins

In a CF patient, the basal PD is more negative, the amiloride response is larger and there is little or no response to chloride-free and isoproterenol solutions. In non-classic CF the nasal PD may be borderline and as yet there is no consensus as to what exactly constitutes an abnormal result.

\section{Clinical Aspects}

As mentioned, CF is a multi-organ disease. The characteristic CF symptoms are chronic sinopulmonary infections, gastrointestinal and nutritional abnormalities, salt loss syndromes and male genital abnormalities resulting in obstructive azoospermia (table 1). Nearly all patients will eventually suffer from chronic sinopulmonary disease. Around $90 \%$ of the patients have pancreatic insufficiency. Postpubertal men are infertile.

\section{Lower Respiratory Tract Disease}

Chronic lung infection and inflammation with intermittent exacerbations is the main problem and limits the length and the quality of life of most CF patients. Bacterial lung infection associated with an increased host inflammatory response is present from early life onwards [32]. Abnormal salt and water balance in the airway leads to retention of viscous secretions and airway obstruction. This largely contributes to perpetuation of infection and inflammation $[2,27]$. However the exact link between CFTR dysfunction and chronic bacterial infection is not fully understood [Donaldson and Boucher, pp. 103-109].
Bacteria most typically associated with CF lung infection are Staphylococcus aureus, Haemophilus influenzae and Pseudomonas aeruginosa. The course of lung disease is invariably progressive, but the rate of progression depends on many factors (table 2). The onset of chronic Pseudomonas infection is usually accompanied by accelerated lung function decline [33]. As a group patients with preserved pancreatic function have less decline in lung function [34]. Genotype, modifier genes, sex, exposure to smoke, poor nutritional status, intensity of treatment and other factors influence disease progression [Cutting, pp. 112-116].

The clinical course is characterized by episodic exacerbations of lung infection. Increased cough is the most common and frequently underestimated first sign of exacerbation. Decreased appetite and exercise tolerance, new crackles on auscultation, new infiltrates on chest $\mathrm{X}$-ray, and a decline in lung function are other possible symptoms and signs [35]. Mostly patients are afebrile and often several of these findings are absent. Exacerbations tend to follow a viral infection [36]. As disease progresses, cough and sputum production increase and exercise capacity becomes more and more limited.

Lung function tests are initially normal but soon peripheral airway obstruction is detected. $\mathrm{FEV}_{1}$, the maximal volume that can be expired in 1 second, is the most commonly used outcome variable to describe disease progression [37]. Ultimately a pattern of mixed obstruction and restriction and hypoxia occur.

Hyperinflation is the first abnormal sign on chest $\mathrm{X}$-ray, soon followed by mucus retention, typically in the right upper lobe. This progresses to increased linear markings, bronchial dilatation, infiltrates, cysts and cor pulmonale. Scores to quantify these changes are used [38].

Many patients have some degree of airway hyperreactivity. Allergic sensitization to Aspergillus antigen occurs in many patients but with disease progression the fullblown syndrome of allergic bronchopulmonary aspergillosis is seen in only $10 \%$ of patients [39]. Minor and major hemoptysis and pneumothorax are complications in patients with advanced disease. Eventually respiratory failure and death occur unless lung transplantation can be performed.

\section{Upper Airway Symptoms}

Nearly all patients have radiographic evidence of pansinusitis, but symptomatic sinusitis is uncommon. Nasal polyps occur frequently. They can be the cause of bothersome nasal obstruction and may require resection [40]. 


\section{Pancreas}

Pancreatic insufficiency is the main cause of failure to thrive in patients with CF. It occurs in about $90 \%$ of patients and is usually present by the age of 1 year [7]. Loose fatty stools, flatulence, abdominal pain, excessive crying and increased appetite are typical symptoms in untreated patients. Fat malabsorption predominates. Noncompliance with intake of pancreatic enzymes remains the main cause of abdominal pain in CF patients. Some genotypes are associated with better preservation of pancreatic function. These patients are more prone to episodes of acute pancreatitis during adolescence and adulthood [41]. Relative glucose intolerance increases with age and CF-related diabetes mellitus amounts to about $20 \%$ in young adults. A worse disease course prior to and following diagnosis is associated with diabetes mellitus [42].

\section{Intestine}

Obstruction of the distal small bowel with viscous meconium leads to meconium ileus in about $15 \%$ of newborn CF infants [4]. Beyond the neonatal period, all CF patients remain susceptible to similar episodes of bowel obstruction, named distal intestinal obstruction syndrome [43]. Crampy abdominal pain and decreased stool production are the initial signs. If not recognized promptly they may progress to total intestinal obstruction with abdominal distension and vomiting. Appendicitis runs an atypical course in CF patients and may lead to a right lower quadrant abdominal abscess because of silent perforation [44]. Intussusception is more frequent. Recurrent rectal prolapse occurs in some CF infants with malabsorption, mainly before the onset of treatment.

\section{Hepatobiliary Tract}

Neonatal cholestasis can lead to the diagnosis of CF but it is not associated with liver disease in later life [5]. An asymptomatic elevation in liver enzymes occurs in many CF patients. Few develop serious biliary cirrhosis and require liver transplant or die from complications of portal hypertension and hypersplenism [45]. Clinical signs such as an enlarged spleen and a palpable enlarged liver with a firm edge suggest liver disease. Liver biopsy provides the most reliable information but is not frequently practiced because of its invasiveness. In most centers liver ultrasound to determine the Westaby score [46] is performed yearly to detect patients with significant liver disease early on.

Diagnosis and Clinical Aspects

\section{Esophagus}

CF infants often have gastroesophageal reflux [47]. Chest physical therapy in the head-down position may worsen reflux. Also in elder CF patients gastroesophageal reflux is common: hyperinflation, coughing, increased inspiratory efforts may all promote gastroesophageal reflux.

\section{Nutrition}

As disease progresses the nutritional status of CF patients tends to become worse: they may be stunted, lighter, and have delayed sexual maturation. Preservation of normal height and weight increase warrants a big effort. CF patients have malabsorption, they have an increased caloric need to fight chronic infection, and they may have an intrinsically higher metabolic rate [48]. They are prone to a deficiency in fat-soluble vitamins, trace elements and essential fatty acids [49]. They have abnormalities in essential fatty acid metabolism [50; Strandvik, p. 132].

\section{Other Symptoms}

Delayed sexual maturation is more common. Postpubertal men are nearly always sterile. Women have diminished fertility and pregnancy may be a threat to their health especially when they have compromised lung function [51].

Excessive salt loss through sweating can lead to acute dehydration [9]. Low salt intake at times combined with excessive salt loss during warm days can lead to metabolic alkalosis in CF infants [9].

Cor pulmonale is a consequence of advanced lung disease and prolonged hypoxia.

Clubbing is seen in most patients with advanced lung or liver disease. Osteoporosis occurs in young adults [52]. With more intense treatment of chronic infection, the typical hypertrophic osteoarthropathy has become rare.

\section{Psychological Issues}

An increasing number of persons with CF live active productive lives despite their disease and treatment burden. Still the frail health and uncertain future puts many at risk of emotional and psychological problems. Finding a job, a life companion and participating in 'main stream life' is not easy when one suffers from a life-shortening disease. As the patient becomes older new complications are added, and the complexity and cost of treatment only increase. Often though, the perceived psychological burden is not proportional to the objective health status of 
the person, i.e. depression can occur in patients who, according to their physician, are doing perfectly well [53, 54].

Parents and also siblings of CF patients have an increased risk of psychological problems because of the emotional stress, the hospital admissions, the financial burden, the time needed to care for the sick child, and the feeling of being left out.

\section{Atypical CF or Non-Classic CF}

A long time ago patients with $\mathrm{CF}$ and preservation of pancreatic function were already being detected, pointing to the variability in the disease spectrum. With the discovery of the CFTR gene, it is increasingly clear that the characteristic CF symptoms starting early in life and associated with classic CF represent just the tip of the iceberg of all the symptoms that may be associated with CFTR dysfunction. There are patients with very mild symptoms and disease onset only during adolescence or adulthood, and patients with just one single clinical feature, e.g. recurrent pancreatitis, sclerosing cholangitis, 'idiopathic' bronchiectasis, male infertility. The latter two categories are described as atypical or non-classic CF. In most the sweat chloride value is equivocal, i.e. 30 $60 \mathrm{mEq} / \mathrm{l}$. The American consensus statement from Rosenstein and Cutting [29] redefined the criteria for the diagnosis of $\mathrm{CF}$ in view of this recent knowledge. They stated that a diagnosis of $\mathrm{CF}$ is retained in patients who have one or more characteristic phenotypic features, or a sibling with CF, or a positive neonatal screening test result, plus laboratory evidence of CFTR abnormality by either a clearly positive sweat test result or two diseasecausing CFTR mutations, or an abnormal nasal PD measurement [29]. However, this definition does not differentiate between patients with classic $\mathrm{CF}$ and patients with milder phenotypes. In a recent European consensus report authors have been more pragmatic: the term classic $\mathrm{CF}$ is reserved for patients with clinical symptoms and a positive sweat test, whereas the term atypical or non-classic CF is reserved for patients in whom the sweat test is equivocal or normal and the diagnosis is supported by more recent diagnostic tools, i.e. two disease-causing mutations or an abnormal nasal PD [55]. This classification is useful but one should not apply it too rigidly. The CF phenotype is really a continuum and there will be overlap between categories.

The diagnostic label CF that describes a life-shortening disease carries a big emotional burden and can be to the patients' disadvantage, e.g. for employment or insurance purposes. Therefore in patients with atypical presentation it should be stressed that they do not have classic CF. It is even more appropriate that patients with disease manifestations in just one organ are named and classified by the disease manifestation itself rather than by the term atypical CF, e.g. sterility because of bilateral absence of the vas deferens, or sclerosing cholangitis or another item from the WHO diagnostic list [56]. Follow-up of these patients is necessary for two reasons: firstly, the clinical features in the individual patient may change over time, e.g. someone with isolated congenital bilateral absence of the vas deferens may develop pulmonary infections, and secondly, clinicians need to expand and share their understanding about what CFTR dysfunction means for the lifetime of a patient.

Patients with an indeterminate sweat chloride, only one mutation identified and an inconclusive nasal PD pose the real diagnostic challenge: at present they cannot be classified because CFTR dysfunction has not been clearly demonstrated. They are at least CF carriers. In the presence of persistent symptoms they need structured follow-up at an appropriate facility and symptomatic treatment. Genetic counseling is important for these patients and their families. Long-term information about this type of patient needs to be collected and improved understanding is likely to follow: the combination of one mutation plus several unfavorable modifier genes is one possibility [55].

\section{Counseling}

Because of the complexity of advising families and relatives, the emotions involved and the risk that correctly given information is misunderstood, over-interpreted or incompletely remembered, counseling should be done by the clinical geneticist. It is also advantageous to dissociate counseling in the family and care for the patient.

\section{Parents of Patients with CF}

The parents of children with CF are obligate heterozygotes. For every subsequent pregnancy of these parents there is a risk of 1 in 4 that the child is affected. If parents desire further pregnancies, they should have access to prenatal testing. When both mutations are known, mutation analysis is done on fetal cells obtained by chorionic villus sampling or amniocentesis [57]. When only one CF-causing CFTR mutation has been identified, further DNA testing is not mandatory: prenatal diagnosis can 
also be performed by segregation analysis of polymorphisms within or linked to the CFTR gene. Because of the emotional stress associated with the decision to interrupt pregnancy, many parents opt for no further pregnancies $[58,59]$.

\section{Siblings of CF Patients}

CF symptoms can be very variable, even within the same family. Therefore CF should always be excluded in siblings, not on clinical grounds but by formal testing. For young siblings it is advised to rule out CF by sweat test rather than by mutation analysis. Knowing whether or not they are a carrier is not desirable for minors; it is only important in siblings for reproductive decisions. There is the worry that parents may overprotect or otherwise stigmatize carriers [60].

\section{Relatives of CF Parents}

Relatives of CF parents have an increased risk of carrying a CFTR mutation and should be informed about it. Some geneticists advise informing couples about their risk status rather than individuals [61], but in times and situations of changing sexual partners this becomes complex. When carrier status is not detected in an individual this diminishes their risk of having a CF child but never totally excludes it: screening tests only consider the most prevalent mutations plus the mutations expressed in the CF patient, provided they were not included in the screening panel.

\section{Conclusion}

CF is a complex multi-organ disease caused by CFTR protein dysfunction.

In the vast majority of cases there is total loss of CFTR function and the diagnosis of CF is clear-cut: the clinical picture is obvious and the clinical diagnosis is supported by sweat test results. Usually a common disease-causing CFTR mutation is identified on both CFTR genes. In a few patients the clinical picture is much milder or even limited to one organ. They are the so-called atypical CF patients. In most of these cases CFTR mutation analysis and bioassays of CFTR protein function will support the diagnosis. Due to their rarity, at times there is no proof that the CFTR mutations found in such patients are in fact disease-causing. We have insufficient knowledge about the long-term prognosis of these atypical cases. These patients do not have classic CF and they should be clearly informed about it.
Many different symptoms can be the first manifestation of CF, the most prevalent being a child with chronic cough and loose stools. A high index of suspicion is the best clue not to miss the diagnosis, especially in milder cases. The pilocarpine iontophoresis sweat test remains the test of choice. The sweat chloride concentration is $>60 \mathrm{mmol} / \mathrm{l}$ in CF patients. Although a simple test, for diagnostic accuracy it should be performed in an experienced laboratory. For difficult cases, CFTR analysis and CFTR bioassays are of additional help. Early diagnosis is necessary to slow down disease progression.

Chronic progressive bacterial sinopulmonary infection and inflammation with intermittent exacerbations are the most typical disease manifestations. Ninety percent of patients have pancreatic insufficiency. Postpubertal men are sterile. During their lifetime CF patients are at risk of disease manifestations and complications in many different organs: sinus, lung, pancreas, liver, intestine, esophagus, bone, joints, etc. The complex mix of possible disease manifestations makes each patient unique. As they become older the number of complications tends to increase: e.g. $20 \%$ of young adult patients have CF-related diabetes mellitus.

Classic CF is a life-shortening disorder and even with the most intense treatment and follow-up the current median survival is around 34 years. This puts an enormous psychological stress on patients and families.

Counseling to prevent disease recurrence in siblings and in the extended family is important but complex. 


\section{References}

1 Report of a Joint Meeting of WHO/ECFTN/ ICF/(M)A/ECFS: The Molecular Genetic Epidemiology of Cystic Fibrosis. Geneva, WHO, 2006. http//:www.who.int/genomics/ publications/en/

2 Boucher RC: Regulation of airway surface liquid volume by human airway epithelia. Pflugers Arch 2003;445:495-498.

3 Rosenstein BJ: Diagnostic methods; in Hodson M, Geddes D (eds): Cystic Fibrosis. London, Arnold, 2006, vol 2, pp 177-188.

4 Mushtaq I, Wright VM, Drake DP, et al: Meconium ileus secondary to cystic fibrosis. The East London experience. Pediatr Surg Int 1998;13:365-369.

$\checkmark 5$ Shapira R, Hadzic N, Francavilla R, et al: Retrospective review of cystic fibrosis presenting as infantile liver disease. Arch Dis Child 1999;81:125-128.

6 Lai HJ, Cheng Y, Farrell PM: The survival advantage of patients with cystic fibrosis diagnosed through neonatal screening: evidence from the United States Cystic Fibrosis Foundation registry data. J Pediatr 2005; 147 : S57-S63.

7 Waters DL, Dorney SF, Gaskin KJ, et al: Pancreatic function in infants identified as having cystic fibrosis in a neonatal screening program. N Engl J Med 1990;322:303-308.

$\rightarrow 8$ Abman SH, Accurso FJ, Butler-Simon N, et al: Role of respiratory syncytial virus in early hospitalizations for respiratory distress of young infants with cystic fibrosis. J Pediatr 1988;113:826-830.

9 Sojo A, Rodriguez-Soriano J, Vitoria JC, et al: Chloride deficiency as a presentation or complication of cystic fibrosis. Eur J Pediatr 1994;153:825-828.

10 Chillon M, Casals T, Mercier B, et al: Mutations in the cystic fibrosis gene in patients with congenital absence of the vas deferens. N Engl J Med 1995;332:1475-1480.

-11 Muniz AE, Bartle S, Foster R: Edema, anemia, hypoproteinemia, and acrodermatitis enteropathica: an uncommon initial presentation of cystic fibrosis. Pediatr Emerg Care 2004;20:112-114.

12 Grosse SD, Boyle CA, Botkin JR, et al: Newborn screening for cystic fibrosis: evaluation of benefits and risks and recommendations for state newborn screening programs. MMWR Recomm Rep 2004;53:1-36.

13 Scotet V, de Braekeleer M, Roussey M, et al: Neonatal screening for cystic fibrosis in Brittany, France: assessment of 10 years' experience and impact on prenatal diagnosis. Lancet 2000;356:789-794.

14 Gibson LE, Cooke RE: A test for concentration of electrolytes in sweat in cystic fibrosis of the pancreas utilizing pilocarpine by iontophoresis. Pediatrics 1959;23:545-549.

$\checkmark 15$ Orenstein DM, Winnie GB, Altman H: Cystic fibrosis: a 2002 update. J Pediatr 2002; 140:156-164
16 LeGrys VA: Sweat testing for the diagnosis of cystic fibrosis: practical considerations. J Pediatr 1996;129:892-897.

17 Guidelines for the performance of the sweat test for the investigation of cystic fibrosis in the UK. Report from the multi-disciplinary working group. July 2002 (http//:www.acb. org.uk).

18 Di Sant'Agnese PA, Darling RC, Perera GA, Shea E: Abnormal electrolyte composition of sweat in cystic fibrosis of the pancreas; clinical significance and relationship to the disease. Pediatrics 1953;12:549-563.

19 Kirk JM, Keston M, McIntosh I, Essa S: Variation of sweat sodium and chloride with age in cystic fibrosis and normal populations: further investigations in equivocal cases. Ann Clin Biochem 1992;29:145-152.

20 Lebecque P, Leal T, De Boeck C, et al: Mutations of the cystic fibrosis gene and intermediate sweat chloride levels in children. Am J Respir Crit Care Med 2002;165:757-761.

21 National Committee for Clinical Laboratory Standards (NCCLS): Sweat Testing: Sample Collection and Quantitative Analysis. Approved guideline C34-A2. Wayne, NCCLS, 2006.

22 Highsmith WE, Burch LH, Zhou Z, et al: A novel mutation in the cystic fibrosis gene in patients with pulmonary disease but normal sweat chloride concentrations. N Engl J Med 1994;331:974-980.

23 Cystic Fibrosis Genotype-Phenotype Consortium: Correlation between genotype and phenotype in patients with cystic fibrosis. $\mathrm{N}$ Engl J Med 1993;329:1308-1313.

24 http://genet.sickkids.on.ca/cgi-bin/WebObjects/MUTATION

25 Schaedel C, Hjelte L, de Monestrol I, et al: Three common CFTR mutations should be included in a neonatal screening programme for cystic fibrosis in Sweden. Clin Genet 1999;56:318-322.

26 Dequeker E, Cuppens H, Dodge J, et al: Recommendations for quality improvement in genetic testing for cystic fibrosis. European Concerted Action on Cystic Fibrosis. Eur J Hum Genet 2000;8(suppl 2):S2-S24.

27 Donaldson SH, Boucher RC: Update on pathogenesis of cystic fibrosis lung disease. Curr Opin Pulm Med 2003;9:486-491.

28 Knowles MR, Paradiso AM, Boucher RC: In vivo nasal potential difference: techniques and protocols for assessing efficacy of gene transfer in cystic fibrosis. Hum Gene Ther 1995;6:445-455.

29 Rosenstein BJ, Cutting GR: The diagnosis of cystic fibrosis: a consensus statement. Cystic Fibrosis Foundation Consensus Panel. J Pediatr 1998;132:589-595.

30 Schuler D, Sermet-Gaudelus I, Wilschanski $\mathrm{M}$, et al: Basic protocol for transepithelial nasal potential difference measurements. J Cyst Fibros 2004;3(suppl 2):151-155.
-31 Standaert TA, Boitano L, Emerson J, et al: Standardized procedure for measurement of nasal potential difference: an outcome measure in multicenter cystic fibrosis clinical trials. Pediatr Pulmonol 2004;37:385-392.

32 Armstrong DS, Grimwood K, Carlin JB, et al: Lower airway inflammation in infants and young children with cystic fibrosis. Am J Respir Crit Care Med 1997;156:1197-1204.

33 Frederiksen B, Koch C, Hoiby N: Antibiotic treatment of initial colonization with Pseudomonas aeruginosa postpones chronic infection and prevents deterioration of pulmonary function in cystic fibrosis. Pediatr Pulmonol 1997;23:330-335.

34 Corey M, Edwards L, Levison H, Knowles M: Longitudinal analysis of pulmonary function decline in patients with cystic fibrosis. J Pediatr 1997;131:809-814.

-35 Rosenfeld M, Emerson J, Williams-Warren J, et al: Defining a pulmonary exacerbation in cystic fibrosis. J Pediatr 2001;139:359-365.

36 Collinson J, Nicholson KG, Cancio E, et al: Effects of upper respiratory tract infections in patients with cystic fibrosis. Thorax 1996; 51:1115-1122.

37 Corey M, McLaughlin FJ, Williams M, Levison $\mathrm{H}$ : A comparison of survival, growth, and pulmonary function in patients with cystic fibrosis in Boston and Toronto. J Clin Epidemiol 1988;41:583-591.

-38 Brasfield D, Hicks G, Soong S, Tiller RE: The chest roentgenogram in cystic fibrosis: a new scoring system. Pediatrics 1979;63:24-29.

-39 Mastella G, Rainisio M, Harms HK, et al: Allergic bronchopulmonary aspergillosis in cystic fibrosis. Eur Respir J 2001;17:10521053.

40 Jorissen MB, De Boeck K, Cuppens H: Genotype-phenotype correlations for the paranasal sinuses in cystic fibrosis. Am J Respir Crit Care Med 1999;159:1412-1416.

-41 De Boeck K, Weren M, Proesmans M, Kerem E: Pancreatitis among patients with cystic fibrosis: correlation with pancreatic status and genotype. Pediatrics 2005; 115:e463e469.

-42 Moran A, Hardin D, Rodman D, et al: Diagnosis, screening and management of cystic fibrosis related diabetes mellitus: a consensus conference report. Diabetes Res Clin Pract 1999;45:61-73.

43 Mascarenhas MR: Treatment of gastrointestinal problems in cystic fibrosis. Curr Treat Options Gastroenterol 2003;6:427-441.

44 Martens M, De Boeck K, Van Der Steen K, et al: A right lower quadrant mass in cystic fibrosis: a diagnostic challenge. Eur J Pediatr 1992;151:329-331.

45 Sokol RJ, Durie PR: Recommendations for management of liver and biliary tract disease in cystic fibrosis. Cystic Fibrosis Foundation Hepatobiliary Disease Consensus Group. J Pediatr Gastroenterol Nutr 1999;28(suppl 1):S1-S13. 
46 Williams SG, Evanson JE, Barrett N, et al: An ultrasound scoring system for the diagnosis of liver disease in cystic fibrosis. J Hepatol 1995;22:513-521.

-47 Heine RG, Button BM, Olinsky A, et al: Gastro-oesophageal reflux in infants under 6 months with cystic fibrosis. Arch Dis Child 1998;78:44-48.

-48 Sinaasappel M, Stern M, Littlewood J, et al: Nutrition in patients with cystic fibrosis: a European Consensus. J Cyst Fibros 2002;1: 51-75.

49 Roulet M, Frascarolo P, Rappaz I, Pilet M: Essential fatty acid deficiency in well nourished young cystic fibrosis patients. Eur J Pediatr 1997;156:952-956.

50 Strandvik B, Gronowitz E, Enlund F, et al: Essential fatty acid deficiency in relation to genotype in patients with cystic fibrosis. J Pediatr 2001;139:650-655.
51 Edenborough FP, Stableforth DE, Webb AK, et al: Outcome of pregnancy in women with cystic fibrosis. Thorax 1995;50:170-174.

52 Conway S: Osteoporosis is cystic fibrosis. J Cyst Fibros 2003;2:161-162.

53 Elgudin L, Kishan S, Howe D: Depression in children and adolescents with cystic fibrosis: case studies. Int J Psychiatry Med 2004;34: 391-397.

54 Kotwicki RJ, Condra L, Vermeulen L, et al: Assessing the quality of life in children with cystic fibrosis. WMJ 2001;100:50-54.

55 De Boeck K, Wilschanski M, Castellani C, et al: Cystic fibrosis: terminology and diagnostic algorithms. Thorax 2005.

56 Classification of cystic fibrosis and related disorders. J Cyst Fibros 2002;1:5-8.
57 Richards CS, Grody WW: Prenatal screening for cystic fibrosis: past, present and future. Expert Rev Mol Diagn 2004;4:49-62.

58 Evers-Kiebooms G, Denayer L, Cassiman JJ, Van den Berghe H: Family planning decisions after the birth of a cystic fibrosis child: the impact of prenatal diagnosis. Scand J Gastroenterol 1988;23:38-46.

59 Mischler EH, Wilfond BS, Fost N, et al: Cystic fibrosis newborn screening: impact on reproductive behavior and implications for genetic counseling. Pediatrics 1998;102:4452.

60 Clarke A: The genetic testing of children. Working Party of the Clinical Genetics Society (UK). J Med Genet 1994;31:785-797.

61 Super M, Schwarz MJ, Malone G, et al: Active cascade testing for carriers of cystic fibrosis gene. BMJ 1994;308:1462-1467. 